Çukurova Üniversitesi Mühendislik Mimarlık Fakültesi Dergisi, 35(2), ss. 325-332, Haziran 2020

Çukurova University Journal of the Faculty of Engineering and Architecture, 35(2), pp. 325-332, June 2020

\title{
İnsan Kaynakları Departmanı için Etmen Tabanlı Sistem Tasarımı
}

\author{
Melek IŞIK ${ }^{* 1}$ \\ ${ }^{1}$ Çukurova Üniversitesi, Mühendislik Fakültesi, Endüstri Mühendisliği Bölümü, Adana
}

Geliş tarihi: $10.04 .2020 \quad$ Kabul tarihi: 30.07 .2020

$\ddot{\mathbf{O z}}$

İşletmelerin verimli bir şekilde faaliyetlerini devam ettirebilmeleri iyi bir insan kaynakları yönetimi sayesinde gerçekleşmektedir. İnsan kaynaklarının akıllı sistemler üzerinden yönetilmesi ile işlemler daha hızlı ve bütüncül yürütülmektedir. İnsan kaynakları gibi karmaşık bir sistemin tasarım ve uygulamasında özerk akıllı etmen sistemlerinin kullanımı yaşanan problemleri çözmek açısından önemlidir. Bu bakış açısıyla, bu çalışmada, etmen tabanlı yaklaşımlardan biri olan Prometheus metodolojisi uygulanarak işletmelerdeki insan kaynakları departmanında yapılan işler için bir tasarım gerçekleştirilmiştir. Prometheus metodolojisinin ve geliştirme ortamının sistem içerisinde uyumluluğu detaylandırılmış ve elde edilen tasarım gösterilmiştir.

Anahtar Kelimeler: Etmen tabanlı sistemler, İnsan kaynakları, Prometheus

\section{Agent Based System Design for the Human Resources Department}

\begin{abstract}
By virtue of a good human resources management that businesses can continue their activities efficiently. Operations are carried out faster and more integrative by managing human resources through intelligent systems. The use of autonomous intelligent agent systems in the design and implementation of a complex system such as human resources is important in solving the problems experienced. From this point of view, in this study, a design is realized for the jobs applied in the human resources department of the enterprises by applying Prometheus methodology, which is one of the agent-based approaches. The compatibility of Prometheus methodology and development environment within the system is detailed and the obtained design is demonstrated.
\end{abstract}

Keywords: Agent based systems, Human resources, Prometheus

*Sorumlu yazar (Corresponding author): Melek IŞIK,demirtasm@cu.edu.tr 


\section{GíRiş}

Toplumsal, ekonomik ve sosyal hayatta teknolojide yaşanan gelişmeler ile birlikte birçok değişim meydana gelmektedir. İnsan kaynakları yönetimi de bu değişimlere uğrayan alanlar arasında yer almaktadır. Son dönemlerde, işletmelerdeki insan kaynakları yönetim birimleri, faaliyetlerini yürütürken iki şeyden yararlanmaktadır. Bunlardan birisi bilgisayarlardan diğeri ise elektronik ortamdan oluşmaktadır [1].

İşletmelerdeki insan kaynakları işlevleri için elektronik olarak kolaylık sağlayan yapay zeka yaklaşımı ile daha hızlı çözümler sağlanabilmektedir. $\mathrm{Bu}$ yaklaşımlardan bir tanesi de etmen tabanlı sistem tasarımıdır. Etmen; "Özerk aktiviteler yapabilen ve bir yazılım ortamına aktarılabilen ayrıca hedef ve isteklerine ulaşabilme gibi yeteneklere sahip bir bilgisayar sistemidir." [2]. Bir amacı veya görevi olan etmenler yapılması gereken planlarını gerçekleştirmek için sistem içerisinde beklerler [3]. Diğer yazılımlar veya bilgisayarlarla iletişime geçen etmenler hedeflerine ulaşırlar ve görev için hazırda beklerler ayrıca kendi amaçları doğrultusunda girişimde bulunurlar [4]. Etmenleri diğer yazılım parçalarından ayıran en önemli özellikleri; özerk olmak, konumlanmak, tepkisellik ve esnekliktir [5].

Literatürde, bu çalışmada olduğu gibi insan kaynakları yönetimi ve etmen tabanlı sistemleri birleştiren çalışmalar çok sınırlıdır. Parker ve Caine [6] basit bir insan kaynakları problemini çözmek için iki alternatif metodolojiyi karşılaştırmıştır. Çalışmada, Markov analizini kullanan geleneksel yaklaşımın karmaşık olduğu ve karar vericiye çok az şey aktardığı gösterilmiştir. Etmen sistem yaklaşımı olan holonik sistem dinamiği yaklaşımının oluşturulması daha kolay ve esneklik sağlayarak karar vericiye kapsamlı bir bakış açısı sağlamıştır. Padgham ve arkadaşları [7] konferans yönetim sistemi ile ilgili Prometheus etmen uygulamasını kullanarak hizmet sektöründe tasarım yapmışlardır. Farklı bir bakış açısıyla bakıldığında, Rahman ve Mahmood [8] bir binada tahliye planlaması yapabilmek için Prometheus metadolojisi kullanmışlardır. Talib ve arkadaşları [9] temel amacı gizlilik ve doğruluk olan bulut veri depolamasının kullanılabilirliği ve bütünlüğünü kolaylaştırmak için Prometheus ile etmen tabanlı sistem tasarlamışlardır. Kaymak ve arkadaşları [10] ise etmen tabanlı sistem tasarım araçlarından olan Prometheus yazılım geliştirme metodolojisini uygulayarak Kanı-İstek-Hedef modeline dayalı çok etmenli sistemin tasarım ve uygulamasını gerçekleştirmişlerdir. Çalışmalarında, örnek kütüphane yönetim sisteminin tasarımı için metodolojideki aşamalar gösterilmiştir. Larioui ve Byed [11] ise birden fazla noktası olan bir ağda karar verme ve rota planlamanın iyi bir şekilde yapılması için Prometheus ile akıllı bir çözüm yolu geliştirmişlerdir.

Literatür incelendiğinde etmen tabanlı sistemlerin Prometheus yöntemi ile işletmelerdeki departmanlar için yapılan çalışmalar yok denecek kadar kısıtlıdır. Bu çalışmada ise, Doğan'ın [1] çalışmasındaki elektronik insan kaynakları yönetimi unsurları için etmen tabanlı sistem tasarım aracı olan Prometheus yazılımı ile problem ele alınmıştır. $\mathrm{Bu}$ tasarım ile amaç, etmen sistem aracılığı ile işletmelerdeki insan kaynakları yönetimi işleyiş̧inde daha hızlı ve doğru yöntemler kullanabilmektir.

\section{YÖNTEM}

Klasik modelleme ve tasarlama sistemlerinden farklılık gösteren sistemlerden birisi de etmen tabanlı sistemlerdir. Etmen tabanlı sistemler için özel tasarım şablonları kullanılmaktadır. Özel şablonlardan biri olan Prometheus, sistemlerin tasarımının yapılmasında ve uygulanmasında önemli rol oynamaktadır. Prometheus metodolojisini tasarlamak için yine aynı isimle bir yazılım geliştirilmiştir. $\mathrm{Bu}$ yöntemde; sistem spesifikasyonları, mimari tasarım ve ayrıntılı tasarım olmak üzere üç temel aşama mevcuttur [12].

Prometheus yönteminin sistem spesifikasyonlarını belirleme aşaması, sistemin hedefleri ve temel fonksiyonları üzerine odaklanmaktadır. $\mathrm{Bu}$ aşamada aynı zamanda etmen tabanlı sistemin 
çevre birimlerle olan iletişim ara yüzleri hazırlanmaktadır. "System specifications" paneli üzerinden sistem spesifikasyonları ana menüsü kullanılarak sistem başlangıç bilgileri girilmektedir.

Mimari tasarım aşamasında, sistemde bulunan etmen tipleri belirlenmektedir. Etmenlerin kendi arasında nasıl iletişimde olacağ 1 sistem spesifikasyonları bölümünden gelen bilgiler ile belirlenmektedir.

Ayrıntılı tasarım aşamasında, etmenlerin detay tasarımı ve sistem içerisindeki işleri nasıl organize edeceği belirlenmektedir. $\mathrm{Bu}$ aşamada etmen tiplerinin karşılaştıkları durumlar karşısında hangi planlarını çalıştıracakları ayrıntılı bir şekilde tasarlanmaktadır. Etmenlerin gerçekleştireceği planlar, başka etmenlerden gelecek mesajlar ile tetiklenerek uygulanmaktadır. Mesajlar, etmenlerin kendi içerisinde veya başka etmenler ile müzakeresi sonucunda iletilmektedir.

Etmen tabanlı sistemlerin tasarımında en yaygın kullanılan Prometheus yöntemini içeren yazılımın adı Prometheus Tasarım Aracidır (Prometheus Design Tool-PDT). Şekil 1'de yazılımın genel görünümü gösterilmiştir.

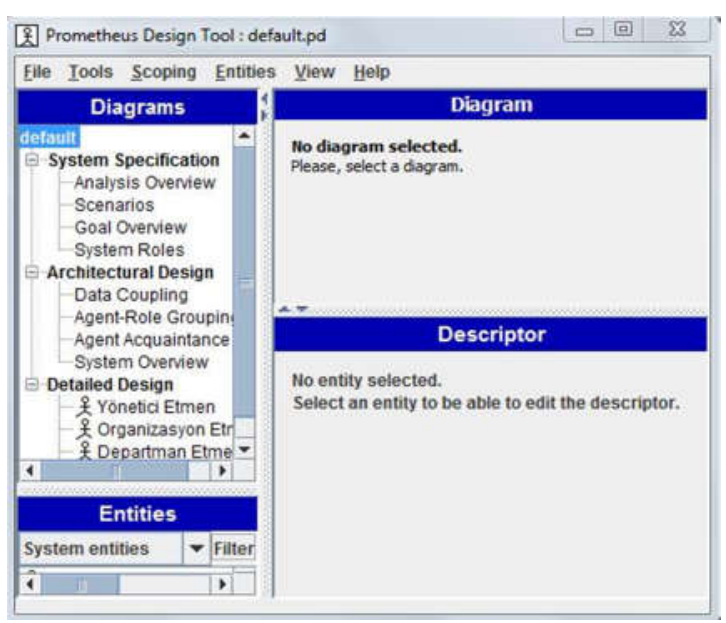

Şekil 1. Prometheus sistem paneli

$\mathrm{Bu}$ çalışmada, Prometheus etmen tabanlı tasarım yazılımı kullanılarak insan kaynakları departmanındaki işleyişi ele alan kavramsal model geliştirilmiştir. $\mathrm{Bu}$ model ile yapılan işler için elektronik olarak yönetim sağlanacaktır.

\section{KAVRAMSAL MODELIN PROMETHEUS YAZILIMI ILE TASARLANMASI}

\subsection{Sistem Spesifikasyonları Așaması}

Prometheus yönteminin ilk aşaması olan sistem spesifikasyonları aşamasında, senaryolar, hedefler ve alt hedefler ayrica bu hedefleri gerçekleştirecek roller belirlenmektedir. Öncelikle, senaryolar oluşturularak modele başlanır. $\mathrm{Bu}$ senaryoları gerçekleştirecek hedefler ortaya konur ve bir yol haritası çizilmiş olunur.

İnsan kaynakları departmanlarında yapılan işlemlerin hangi işler olduğu konusunda Doğan'ın [1] çalışması bizi yönlendirmiştir. Tespit edilen hususlara göre sistemde yapılması hedeflenen senaryolar oluşturulmuştur. Oluşturulan senaryolar aşağıdaki gibi tanımlanmıştır:

- Mülakata dayalı işçi alma,

- Performansa göre işçi çıkarma,

- Özlük bilgilerinin işlenmesi,

- Eğitim takvimlerinin oluşturulması,

- Oryantasyon programının düzenlenmesi,

- Kariyer planlamasının yapılması.

Sistem senaryolarının gerçekleşmesi durumunda hangi rollerin aktif olacağ belirlenmektedir. Senaryolara göre hazırlanan sistemdeki hedefler ve rol tanımlamaları Şekil 2'deki gibi tanımlanmıştır.

İnsan kaynakları için olması gereken roller üç başlık altında toplanmıştır. Sistemdeki insan kaynakları rol tanımları; "işe alım ve işten çıkarma yönetimi", "eğitim yönetimi" ve "kariyer yönetimi” gibi tanımlanmaktadır. Her bir rolün altında gerçekleştirilmesi gereken hedefler mevcuttur. Böylece, insan kaynakları için gerçekleştirilmesi gereken hedefler bir role atanarak işlemler gruplandırılmış ve hangi işlemlerin yapılacağı belirlenmiştir. 


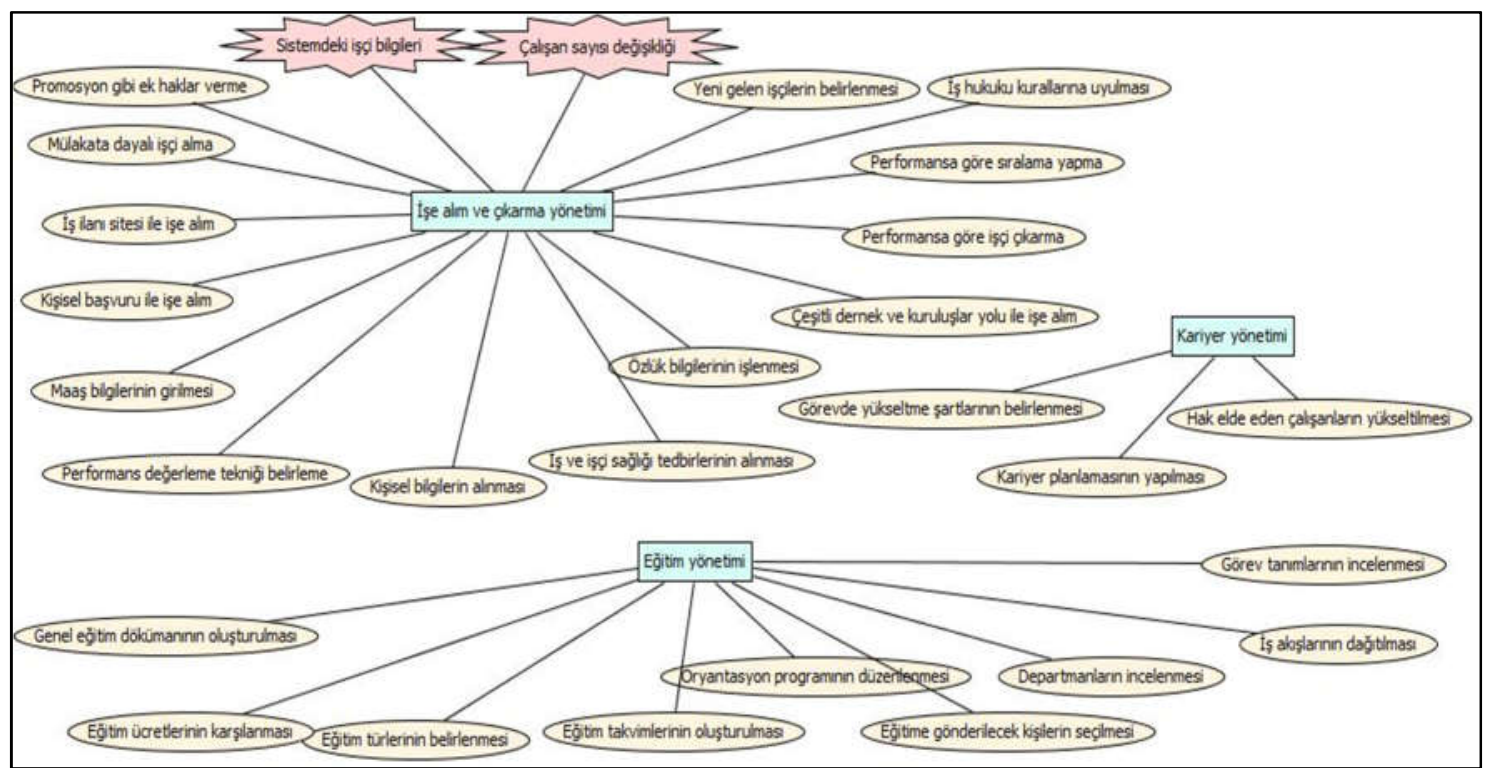

Şekil 2. Sistem rol tanımlamaları

İşe alım ve çıkarma yönetimi rolündeki hedefler aşağıda sıralanmıştır:

- Mülakata dayalı işçi alımı,

- Yeni gelen işçilerin belirlenmesi,

- İş ilanı sitesi ile işe alım,

- Kişisel başvuru ile işe alım,

- Çeşitli dernek ve kuruluşlar yolu ile işe alım,

- Performansa göre işçi çıkarma,

- Performans değerleme tekniği belirleme,

- Performansa göre siralama yapma,

- Promosyon gibi ek haklar verme,

- Özlük bilgilerinin işlenmesi,

- Kişisel bilgilerin alınması,

- Maaş bilgilerinin girilmesi,

- İş hukuku kurallarına uyulması,

- İş ve işçi sağlığı tedbirlerinin alınması,

Eğitim yönetimi rolündeki hedefler ise şunlardır:

- Eğitim takvimlerinin oluşturulması,

- Eğitime gönderilecek kişilerin seçilmesi,

- Eğitim türlerinin belirlenmesi,

- Eğitim ücretlerinin karşılanması,

- Oryantasyon programının düzenlenmesi,

- Genel eğitim dokümanının oluşturulması,

- Departmanların incelenmesi,

- Görev tanımlarının incelenmesi,
- İş akışlarının dağıtılması,

Kariyer yönetimi rolündeki hedefler de aşağıda belirlendiği gibidir:

- Kariyer planlamasının yapılması,

- Görevde yükselme şartlarının belirlenmesi,

- Hak elde eden çalışanların yükseltilmesi.

Sistemdeki işçi bilgileri ve çalışan sayısı değişikliği gibi sistem başlangıç bilgileri bu aşamada yazılım üzerinde tasarlanmaktadır. $\mathrm{Bu}$ hedefler gerçekleştirildiğinde insan kaynakları departmanı açısından işletmelere daha hızlı bilgi akışının sağlanması ve elektronik olarak bir bütün şeklinde sistemin yönetilmesi amaçlanmaktadır. İşgücü tasarrufu sağlanarak daha yetkin elemanlar yetiştirilecektir. Böylece insan kaynakları departmanı daha verimli bir iş planı ile yönetilmiş olacaktır.

\subsection{Mimari Tasarım Aşaması}

$\mathrm{Bu}$ aşama, sistem spesifikasyonları aşamasında belirlenen rolleri ve etmenleri belirleyerek gruplandirmaktadır. Etmenler belirlendikten sonra etmenler arasında protokoller yazılarak müzakere sistemi oluşturulmaktadır. Şekil 3'te etmen ve rol tanımlamaları görülmektedir. 


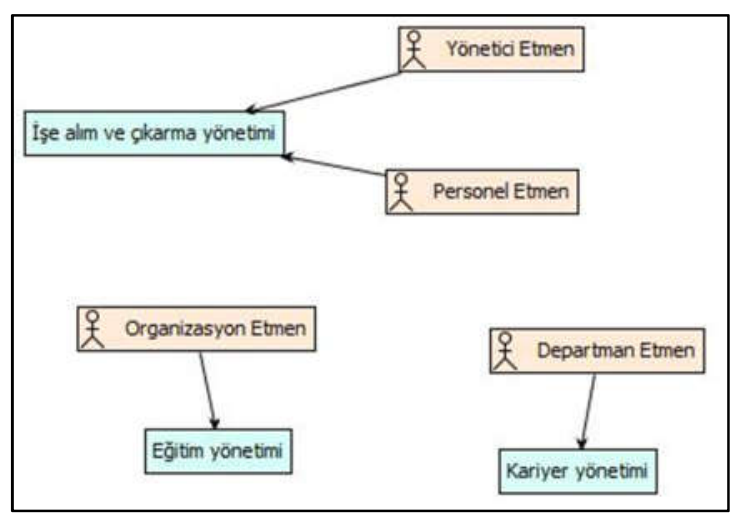

Şekil 3. Rol etmen bağlantıları

Şekil 3'te işe alım ve işten çıkarma yönetimi Yönetici Etmen ve Personel Etmen tarafindan yürütülmektedir. Ayrıca Organizasyon Etmen eğitim yönetimi rolünü ve Departman Etmen de kariyer yönetimi rolünü üstlenmiştir. Şekil 4'de ise etmenler ve aralarındaki protokoller gösterilmektedir. Yönetici Etmen ve Personel Etmen arasında yönetim protokolü, Personel Etmen ve Departman Etmen arasında bilgi protokolü, Personel Etmen ve Organizasyon Etmen arasında iletişim protokolü mevcuttur. $\mathrm{Bu}$ protokollerde mesajlaşma yöntemi ile birbirleri arasında etkileşim söz konusu olmaktadır. Çalışan sayısı değişikliği ve sistemdeki işçi bilgileri de Yönetici Etmen tarafından işleme alınmaktadır.

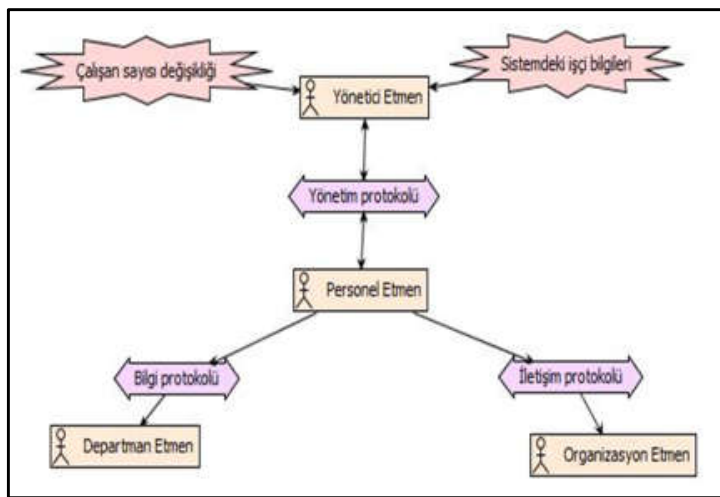

Şekil 4. Etmenler ve protokollerin gösterimi

Etmen tipleri kendilerine gelen çevresel olayları çözerken diğer etmen tipleri ile etkileşime geçmektedirler. Şekil 5'de Yönetici Etmen tipi ile Personel Etmeni arasındaki müzakere protokolü görülmektedir. Etmenler arasındaki iletişim de kurulduktan sonra sistemimizin mimari tasarım aşaması tamamlanmış olmaktadır. Bu şekilde insan kaynakları için iletişim halinde olacak etmenler belirlenmiş ve işlemler daha eşzamanlı yürütülmeye başlanmış olunmaktadır.

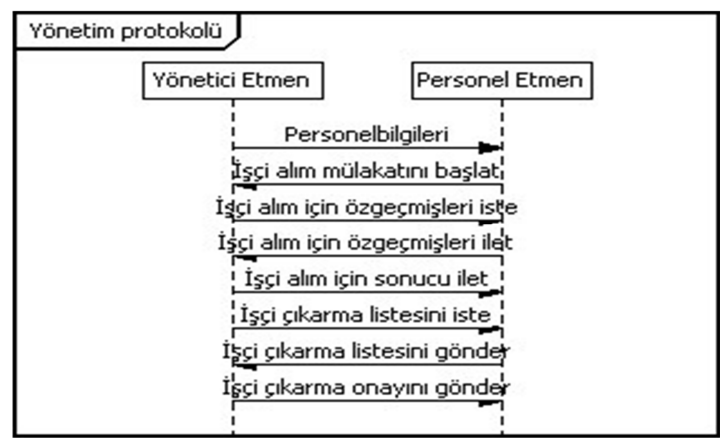

Şekil 5. Yönetici-personel
müzakere protokolü

\subsection{Ayrıntılı Tasarım Aşaması}

$\mathrm{Bu}$ aşamada, etmenlerin mesaj tetiklemesiyle hangi planlarını çalıştıracakları ve hangi veri tabanı üzerinde işlem yapacakları tanımlanmaktadır. Mesajlar, etmenlerin kendi içerisinde olabildiği gibi diğer etmenlerden de gelebilmektedir. İnsan Kaynakları Departmanı için mimari tasarım aşamasında oluşturulan etmenlerin detayları bu aşamada verilmiştir.

Şekil 6'da Yönetici Etmen tipinin ayrıntılı tasarımı gösterilmektedir. Yönetici Etmen sistemi tetikleyerek Personel, Departman ve Organizasyon Etmenleri oluşturma planları gerçekleşir. Yeni işçiyi bildirme, personel değiştirme ve çıkarılan işçiyi Personel Etmene bildirme planlarını da gerçekleştirerek özgeçmiş veri tabanı güncellenir. Yönetici Etmenden personel bilgileri, işçi alım için özgeçmişleri iste, işçi alım için sonucu ilet, işçi çıkarma listesini iste ve işçi çıkarma onayını gönder mesajları Personel Etmene gönderilir. Bu mesajlara cevap olarak Personel Etmenden işçi alım mülakatını başlat, işçi alım için özgeçmişleri ilet ve işçi çıkarma listesini gönder mesajları Yönetici Etmene gönderilir. Bu şekilde, insan kaynakları için önemli olan Yönetici Etmen ile Personel Etmen arasında elektronik olarak bir köprü kurulmuş olur. 
Şekil 7'de ise Personel Etmenin ayrıntılı tasarımı gösterilmektedir. Personel özlük bilgilerini veri tabanına ekleme planıyla gelen personel bilgileri bordro bilgileri veri tabanına eklenir. Mülakatlar sonucu alınan işçileri belirleme planı ile gelen özgeçmişlerin ve iletişim bilgilerinin Yönetici Etmene gönderilmesi ve Yönetici Etmenin onay1 sonrasında işe başlaması karar verilen kişilerin bilgileri sisteme dahil edilmesi söz konusudur. Görüşmeler sonucunda çıkarılacak işçileri belirleme planıyla Yönetici Etmenin onayıyla kişi bilgileri güncellenir. Performans değerleme tekniklerini uygulama planıyla performansı iyi olan çalışanlara kariyer planları oluşturularak promosyonlar veri tabanına eklenir. İş hukuku ve işçi sağlığı planları çalıştırılır. Personel Etmen burada kilit rolü üstlenmiştir. Etmenler arasında müzakere yaparak insan kaynakları işleyişini dengede tutmaktadir.

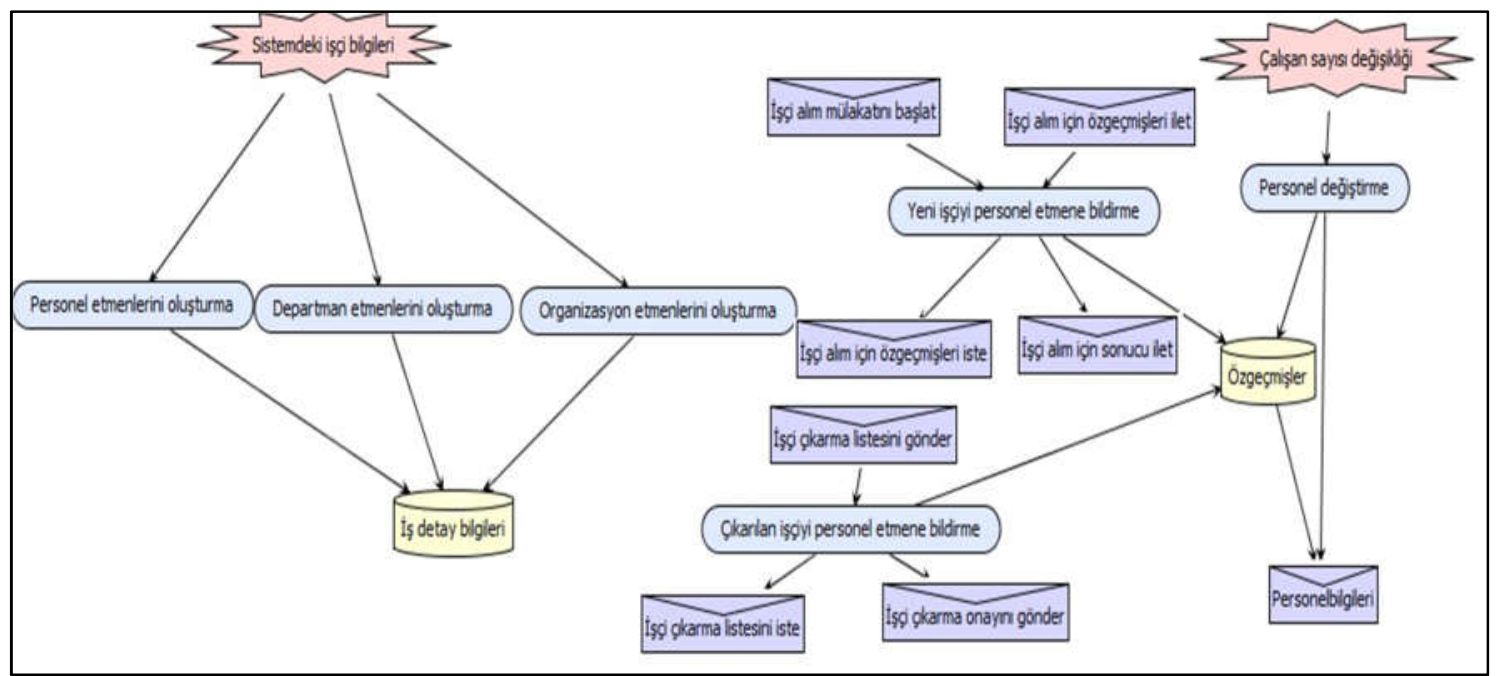

Şekil 6. Yönetici etmen-ayrıntılı tasarım

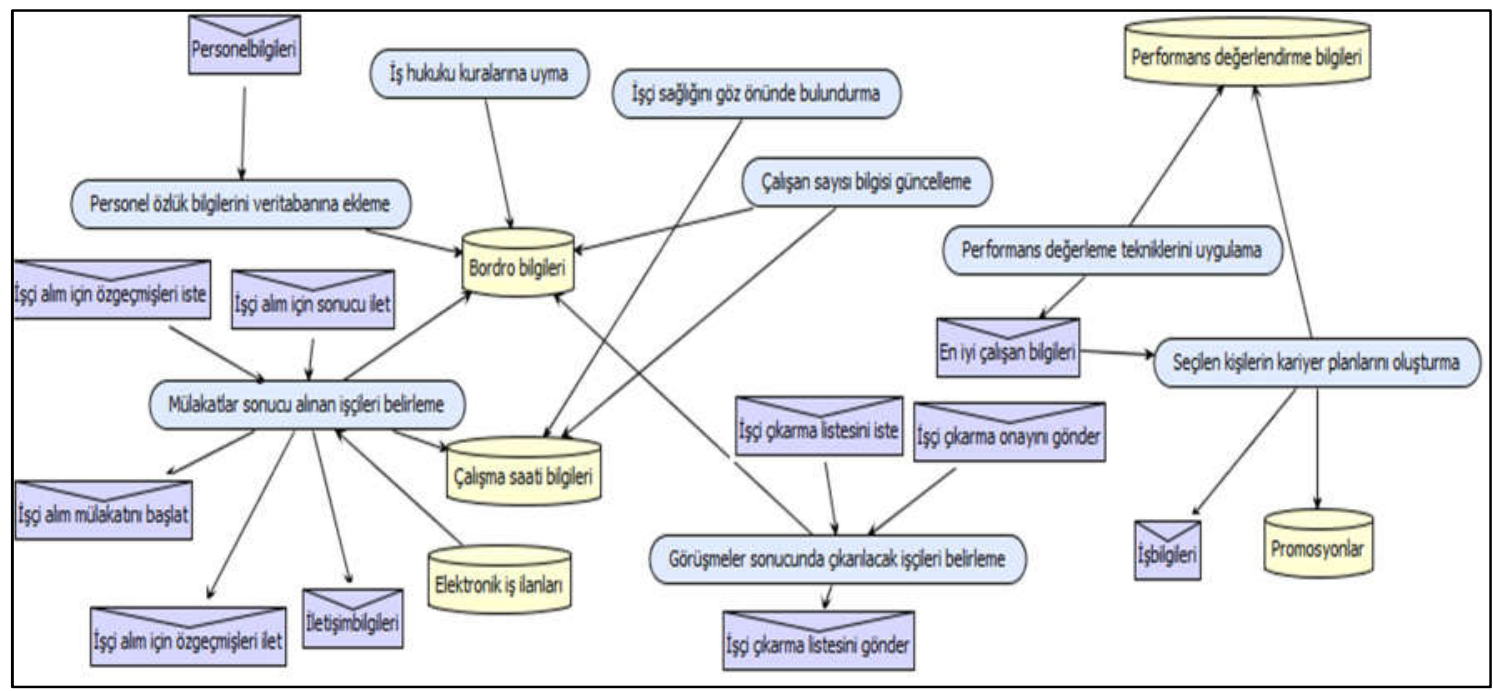

Şekil 7. Personel etmen-ayrıntılı tasarım 


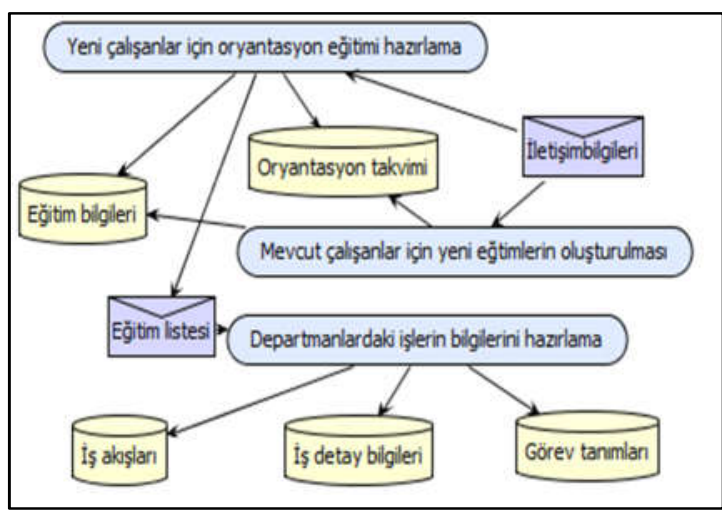

Şekil 8. Organizasyon etmen-ayrıntılı tasarım

Şekil 8'de organizasyon etmeni ayrıntılı tasarımı gösterilmiştir. Yeni çalışanlar için oryantasyon eğitimi hazırlama planıyla oryantasyon ve eğitim bilgileri kaydedilir. Mevcut çalışanlar için yeni eğitimlerin oluşturulması planıyla çalışanların güncel eğitimleri görmesi sağlanır. Ayrıca departmanlardaki işlerin bilgileri hazırlanarak işçilere iş bilgileri rehber olarak gösterilmektedir. Böylece, insan kaynakları departmanında yeni işe başlayan veya mevcut çalışanların düzenli eğitim takvimleriyle kişisel gelişimleri Organizasyon Etmen aracılığıyla sağlanmış olur.

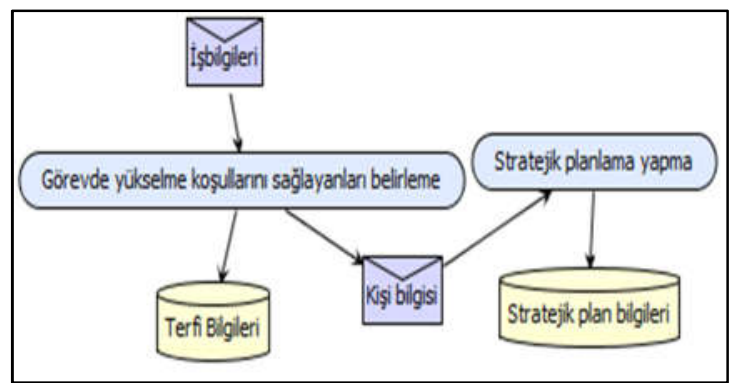

Şekil 9. Departman etmen-ayrıntılı tasarım

Şekil 9'da Departman Etmenin ayrıntılı tasarımı gösterilmektedir. Görevde yükselme koşularını sağlayanları belirleme planıyla sistemin stratejik planı yapılarak terfiler işçilere verilmektedir. Departman Etmen aracılığg ile başarılı kişilere hakları teslim edilerek motive edilmesi sağlanmaktadır. Bu şekilde, insan kaynakları için önemli unsurlarından birisi olan kazanılmış haklar çalışanlara teslim edilmiş olunur.
Etmen tabanlı sistem geliştirilmesinde son aşama bir yazılım aracılığı ile uygulama yapılmasıdır. Fakat, farklı platform kullanımı gerektirdiği için Prometheus yöntemi içerisine dahil edilmemiştir. $\mathrm{Bu}$ tasarım ile insan kaynakları işleyişinin elektronik olarak birbiriyle konuştuğu bir sistem tasarımı gerçekleştirilmiştir. Bu sistem ile verimli bir yönetim sistemi gerçekleştirilerek veri kayıplarının önüne geçilmesi sağlanmaktadır.

\section{SONUÇ}

$\mathrm{Bu}$ çalışmada, etmen tabanlı sistemlerin tasarımında kullanılan yazılım ile işletmelerdeki insan kaynakları departmanlarının yaptığı işlemler için tasarım yapılmıştır. Model, geleneksel modelleme ve tasarlama yöntemlerinden farklılık göstermektedir. Prometheus tasarım yönteminin sahip olduğu üç aşama incelenmiş ve insan kaynakları işlemleri için gerekli işlerin tasarımı sağlanmıştır. $\mathrm{Bu}$ yazılım ile takım çalışması desteklenmiş ve elektronik olarak sistemin yönetilmesi bir bütün halinde sağlanmıştır. $\mathrm{Bu}$ çalışma ile hedeflenen, insan kaynakları işleyişinin kağıt ve dokümantasyon gibi maliyetlerden azaltarak daha verimli bir yönetim bakış açısı kazandırmaktır. Çalışanlar için çizelgeleme faaliyetlerini düzenleyerek sistemi daha hızlı hale getirmek amaçlanmıştır. Gelecek çalışmalarda, yazılımın kodlama yapılan platformlarda gerçekleştirilerek sistemin daha verimli hale getirilmesi düşünülmektedir.

\section{KAYNAKLAR}

1. Doğan, A., 2011. Elektronik İnsan Kaynakları Yönetimi ve Fonksiyonları, 51-80.

2. Wooldridge, M., Jennings N.R., 1995. Intelligent Agents: Theory and Practice, The Knowledge Engineering Review, 10(2), 115-152.

3. Hahn, C., Madrigal-Mora C., Fischer K., 2009. A Platform-independent Metamodel for Multiagent Systems, Autonomous Agents and Multiagent Systems, 18(2), 239-266.

4. Bellifemine, F.L., Caire, G., Greenwood, D., 2007. Developing Multi-agent Systems with JADE, John Wiley \& Sons, (7), 303. 
5. Wooldridge, M., 2009. An Introduction to Multiagent Systems, England: John Wiley \& Sons, Ltd, (2), 368.

6. Parker, B., Caine D., 1996. Holonic Modelling: Human Resource Planning and the Two Faces of Janus, International Journal of Manpower, 17(8), 30-45.

7. Padgham, L., Thangarajah J., Winikoff M., 2007. The Prometheus Design tool-a Conference Management System Case Study, In International Workshop on Agent-Oriented Software Engineering, Springer, 197-211.

8. Rahman, A.,. Mahmood A. K., 2008. Agentbased Simulation using Prometheus Methodology in Evacuation Planning, In 2008 International Symposium on Information Technology, IEEE, 1-8.

9. Talib, A.M., Atan, R., Abdullah, R., Murad, M.A., 2011. Multi Agent System Architecture Oriented Prometheus Methodology Design to Facilitate Security of Cloud Data Storage, Journal of Software Engineering, 5(3), 78-90.

10. Kaymak, Y., Teket K.D., Demirci, S., Getir, S., Erdur, R.C., Kardaş, G., 2012. JACK Kanıİstek-hedef Modeline dayalı Çok-etmenli bir Kütüphane Yönetim Sisteminin Prometheus Metodolojisi ile Geliştirilmesi, 6. Ulusal Yazılım Mühendisliği Sempozyumu, 121-128.

11. Larioui, J., Byed A.E., 2020. Multi-Agent System Architecture Oriented Prometheus Methodology Design for Multi-modal Transportation, International Journal, 8(5), 2118-2125.

12. Padgham, L., Winikoff M., 2005. Developing Intelligent Agent Systems: A Practical Guide, John Wiley \& Sons, (13), 241. 